08,09

\title{
Зависимость характеристик узких линий люминесценции в наноалмазах от параметров возбуждения и температуры
}

\author{
(ㄱ С.А. Грудинкин, А.Н. Смирнов, В.Ю. Давыдов, В.Г. Голубев \\ Физико-технический институт им. А.Ф. Иофрфе РАН, \\ Санкт-Петербург, Россия \\ E-mail: grudink.gvg@mail.ioffe.ru
}

Поступила в Редакцию 14 апреля 2021 г.

В окончательной редакции 18 апреля 2021 г.

Принята к публикации 18 апреля 2021 г.

\begin{abstract}
Исследовано влияние параметров возбуждающего излучения и температуры на спектральные характеристики узких линий фотолюминесценции наноалмазов, полученных методом химического газофазного осаждения. Показано, что соотношение интенсивностей линий в спектре зависит от длины волны и мощности возбуждающего излучения. Для некоторых линий с увеличением мощности наблюдался также сдвиг положения их максимума и уширение. После облучения наноалмазов лазерным лучом с плотностью мощности $\sim 1.2 \cdot 10^{5} \mathrm{~W} / \mathrm{cm}^{2}$ происходят изменения относительной интенсивности линий. При увеличении температуры в диапазоне 79-300 K наблюдается температурное гашение их интенсивности.
\end{abstract}

Ключевые слова: алмаз, центры окраски, фотолюминесценция, химическое газофазное осаждение.

DOI: 10.21883/FTT.2021.08.51166.086

\section{1. Введение}

Оптически активные центры окраски в алмазе обладают большими перспективами применения в качестве однофотонных когерентных источников излучения для квантовой информатики и люминесцентных маркеров для биомедицины [1-5]. Особый интерес проявляется к наноалмазам с введенными центрами окраски. Он вызван возможностью управления спонтанной эмиссией центров окраски за счет интегрирования наноалмазов в наноплазмонные и нанофотонные структуры, а также их способностью проникать в биологические ткани $[1,6,7]$. Для практического применения в качестве однофотонных источников излучения и люминесцентных биомаркеров требуются центры окраски, излучающие в видимом и ближнем инфракрасном диапазоне, обладающие интенсивной и узкой бесфононной линией (БФЛ) фотолюминесценции (ФЛ), высоким значением фактора Дебая-Веллера, низкой спектральной диффузией и высокой фотостабильностью $[4,5]$. Перечисленным требованиям удовлетворяют примесно-вакансионные комплексы в алмазе: кремний-вакансия, германий-вакансия, олово-вакансия, свинец-вакансия [1], a также Cr-содержащие центры [8] и Ni/Si-содержащие центры [9].

Сравнительно недавно в спектрах синтезированных методом химического газофазного осаждения (CVD) алмазных пленок и наноалмазов обнаружен новый тип узких линий ФЛ. Структура и состав ответственных за эти линии оптически активных центров до настоящего времени не установлены [10-16]. В спектрах ФЛ поликристаллических пленок зарегистрированы узкие линии с максимумами БФЛ в спектральном диапа- зоне 620-760 nm и с шириной на половине амплитуды (FWHM) приблизительно $3 \mathrm{~nm}$ при комнатной температуре [10]. Оптические центры окраски с БФЛ в ближней инфракрасной области получены путем активации дефектов в монокристаллических алмазах в процессе высокотемпературного отжига [12,13]. В наноалмазах, выращенных на подложке сапфира, обнаружены однофотонные центры излучения с узкой БФЛ на длине волны $\sim 780 \mathrm{~nm}$ [15]. Линии с FWHМ $\sim 1-2.5 \mathrm{~nm}$ в области длин волн 650-750 nm наблюдались в спектрах ФЛ наноалмазов на кремниевой и иридиевой подложках [14]. В работе [16] в видимом и ближнем ИК спектральном диапазоне обнаружены узкие линии (FWHM $\sim 1-2 \mathrm{~nm}$ ) в наноалмазах, полученных методом реактивного ионного травления в кислородной плазме алмазных частиц, синтезированных методом микроволнового химического газофазного осаждения (MWCVD) на кремниевой подложке. При этом в спектрах практически отсутствовал широкополосный фоновый сигнал ФЛ.

Предположительно, оптически активные центры, ответственные за узкие линии ФЛ, являются точечными дефектами, представляющими собой морфологические дефекты, локализованные на двойниковых границах или поверхности кристаллитов $[10,14,15]$. На формирование таких дефектов могут влиять примеси водорода [13] и азота [14]. Показано, что наблюдаемые в работах $[10,12-14]$ оптически активные центры являются однофотонными источниками излучения и, возможно, могут составить конкуренцию хорошо известным примесно-вакансионным комплексам в алмазе. Существенным препятствием к практическому применению наноалмазов с узкополосными источниками излучения является то, что процесс их формирования не является 
надежно контролируемым. Это приводит к тому, что в спектрах ФЛ количество наблюдаемых узких линий и их спектральные положения различны для каждого ансамбля наноалмазов [16]. Для развития контролируемых методов создания оптически активных центров в наноалмазах необходимы исследования спектральных характеристик центров с целью дальнейшего выявления их структуры и механизмов образования.

Целью настоящей работы являлось исследование влияния параметров возбуждающего излучения (длины волны и плотности мощности) и температуры внешней среды на спектральные характеристики узких линий ФЛ наноалмазов, полученных методом реактивного ионного травления в кислородной плазме алмазных частиц, синтезированных методом MWCVD на кремниевой подложке.

\section{2. Методика эксперимента}

Алмазные частицы были получены методом MWCVD при следующих параметрах осаждения: микроволновая мощность - $600 \mathrm{~W}(2.45 \mathrm{GHz})$, температура подложки $-700^{\circ} \mathrm{C}$, расход водорода - $500 \mathrm{sccm}$, концентрация метана - 2.8\%, рабочее давление в реакторе - 15 Torr. Время роста частиц составляло $\sim 40 \mathrm{~min}$. В качестве центров зародышеобразования использовались наноалмазы детонационного синтеза с характерным размером $\sim 4 \mathrm{~nm}$, которые контролируемым образом наносились на кремниевую подложку методом аэрозольного распыления [17]. Концентрация наноалмазов детонационного синтеза на поверхности подложки составляла $\sim 10^{6} \mathrm{~cm}^{-2}$.

Реактивное ионное травление алмазных частиц осуществлялось в кислородно-азотной смеси $\left(\mathrm{O}_{2}-\right.$ $20 \mathrm{vol} \%, \mathrm{~N}_{2}-80 \mathrm{vol} \%$ ) при следующих параметрах: микроволновая мощность - $250 \mathrm{~W}(2.45 \mathrm{GHz})$, температура подложки - 500-600 ${ }^{\circ} \mathrm{C}$, расход кислородноазотной смеси - $100 \mathrm{sccm}$, рабочее давление в реактоpe -10 Torr, время травления $-\sim 30 \mathrm{~min}$. Подробное описание процессов роста, контроля размеров частиц в процессе роста и реактивного ионного травления изложены в работах $[18,19]$. Спектры ФЛ регистрировались от ансамблей наноалмазов, образовавшихся после травления исходных частиц.

Измерения методами спектроскопии комбинационного рассеяния света (КРС) и микрофотолюминесценции ( $\mu$-ФЛ) проводились на спектрометре Horiba Jobin Yvon T64000, оснащенном конфокальным микроскопом, охлаждаемой жидким азотом кремниевой ПЗС матрицей и дифракционной решеткой $1800 \mathrm{lines} / \mathrm{mm}$. При измерениях использовались длины волн возбуждающего излучения $532 \mathrm{~nm}$ и $633 \mathrm{~nm}$. Спектры КРС измерялись при комнатной температуре в пятне $\sim 1 \mu \mathrm{m}$ на образце, полученном с использованием объектива $100 \times(\mathrm{NA}=0.9)$. Все измерения спектров КРС проводились в режиме тройного монохроматора со сложением дисперсии, что обеспечивало максимальное спектральное разрешение $0.35 \mathrm{~cm}^{-1}$. Измерения низкотемпературной $\mu$-ФЛ проводились в приставке для микроскопии Linkam THMS600. Для фокусировки падающего пучка в пятно диаметром $\sim 2 \mu \mathrm{m}$ при измерениях спектров ФЛ использовался объектив Leica PL FLUOTAR $50 \times(\mathrm{NA}=0.55)$ с большим рабочим расстоянием.

\section{3. Экспериментальные результаты и их обсуждение}

Спектры ФЛ ансамбля наноалмазов, измеренные при комнатной температуре, демонстрируют набор узких линий и БФЛ центра кремний-вакансия в отрицательном зарядовом состоянии $\left(\mathrm{SiV}^{-}\right)$с максимумом на длине волны $738.1 \mathrm{~nm}$ и с FWHM равной $\sim 6.5 \mathrm{~nm}$ (рис. 1). Центры окраски $\mathrm{SiV}^{-}$введены в алмазные частицы в процессе их роста вследствие вхождения в решетку алмаза атомов кремния, образовавшихся в результате травления подложки кремния атомарным водородом [18]. Линия $572.5 \mathrm{~nm}$ является линией КРС алмаза, соответствующей ТО-фонону $\left(1332 \mathrm{~cm}^{-1}\right)$ симметрии $\mathrm{F}_{2 g}[20]$. На вставке приведен спектр КРС данного ансамбля наноалмазов с FWHM $\sim 2.5 \mathrm{~cm}^{-1}$ для ТО-фонона. В спектрах ФЛ наноалмазов практически отсутствует фоновой сигнал в виде широкой полосы ФЛ с максимумом в видимой области спектра, которая связана с присутствием неупорядоченного $s p^{2}$-гибридизованного углерода.

В спектре ФЛ, зарегистрированном при плотности мощности возбуждающего излучения $2.5 \cdot 10^{4} \mathrm{~W} / \mathrm{cm}^{2}$,

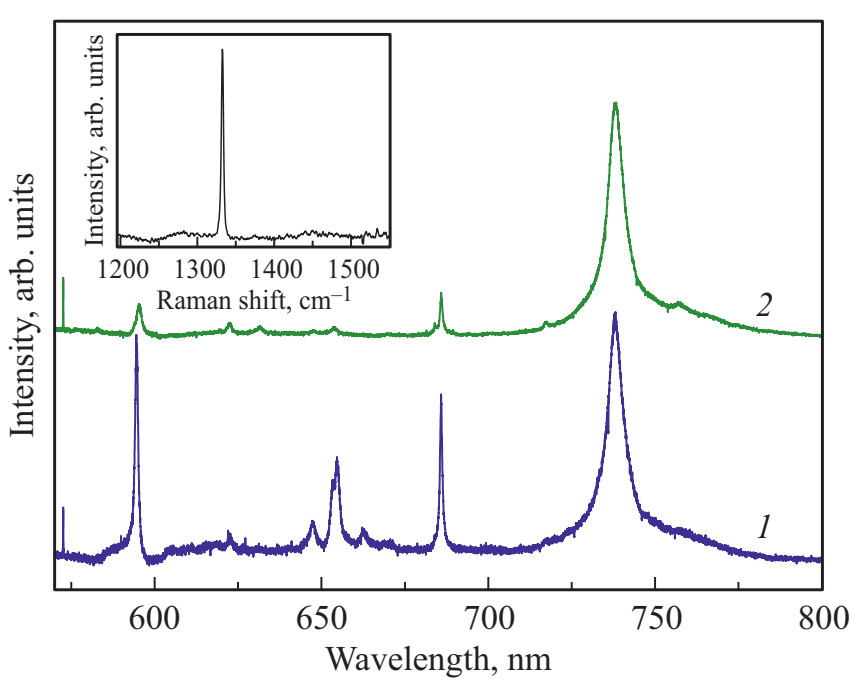

Рис. 1. Спектры ФЛ ансамбля наноалмазов, измеренные с использованием возбуждения $532 \mathrm{~nm}$ и плотности мощности возбуждающего излучения $2.5 \cdot 10^{4} \mathrm{~W} / \mathrm{cm}^{2}$ (1) и $1.2 \cdot 10^{5} \mathrm{~W} / \mathrm{cm}^{2}(2)$. Спектры измерены при $T=300 \mathrm{~K}$ и нормированы на амплитуду БФЛ центра окраски $\mathrm{SiV}^{-}(738.1 \mathrm{~nm})$. На вставке представлен спектр КРС данного ансамбля наноалмазов. 
наблюдаются интенсивные узкие линии с максимумами на длинах волн 594.6 (1.2) nm, $622.2 \mathrm{~nm}, 647.4$ (2.2) nm, две близко расположенные линии в области $654 \mathrm{~nm}$, а также линии $662.6 \mathrm{~nm}$ и $685.9(0.8) \mathrm{nm}$. В скобках указана FWHM в нанометрах для тех линий, в которых она надежно определялась. При плотности мощности возбуждения $1.2 \cdot 10^{5} \mathrm{~W} / \mathrm{cm}^{2}$ (спектр 2) интенсивность узких линий уменьшается (за исключением линии $622.2 \mathrm{~nm})$. Две близко расположенные линии в области $654 \mathrm{~nm}$ практически исчезают, и появляется слабая линия $631.5 \mathrm{~nm}$. Линии 594.6 и $685.9 \mathrm{~nm}$ сдвигаются в длинноволновую область спектра, соответственно, на 0.7 и $0.1 \mathrm{~nm}$. С увеличением плотности мощности накачки FWHM линий 594.5 и $685.9 \mathrm{~nm}$ увеличивается с 1.2 до $2 \mathrm{~nm}$ и с 0.9 до $1 \mathrm{~nm}$, соответственно.

На рис. 2 приведены спектры одного и того же ансамбля наноамазов, измеренные при возбуждении на длинах волн $532 \mathrm{~nm}$ (спектр 1) и $633 \mathrm{~nm}$ (спектр 2). В обоих спектрах помимо БФЛ центра $\mathrm{SiV}^{-}(738.1 \mathrm{~nm})$ наблюдаются линии 685.8, 690.4, 697.3 и $701.8 \mathrm{~nm}$. При возбуждении спектра ФЛ на длине волны $633 \mathrm{~nm}$ линия $690.4 \mathrm{~nm}$ имеет большую интенсивность, чем линия $685.8 \mathrm{~nm}$. В спектре ФЛ, зарегистрированном при возбуждении на длине волны $633 \mathrm{~nm}$ наблюдаются также линии 678.9, 715.0 и $791.4 \mathrm{~nm}$. Таким образом, регистрируемый набор линий и соотношение интенсивности линий ФЛ зависит от длины волны возбуждающего излучения.

Спектры ФЛ при различной плотности мощности возбуждающего излучения на длине волны $633 \mathrm{~nm}$ показаны на рис. 3. Спектры нормированы на амплитуду линии $685.8 \mathrm{~nm}$. Установлено, что при плотности мощности свыше $1.2 \cdot 10^{5} \mathrm{~W} / \mathrm{cm}^{2}$ наблюдается сдвиг и уширение БФЛ центра $\mathrm{SiV}^{-}$, обусловленный нагревом наноал-

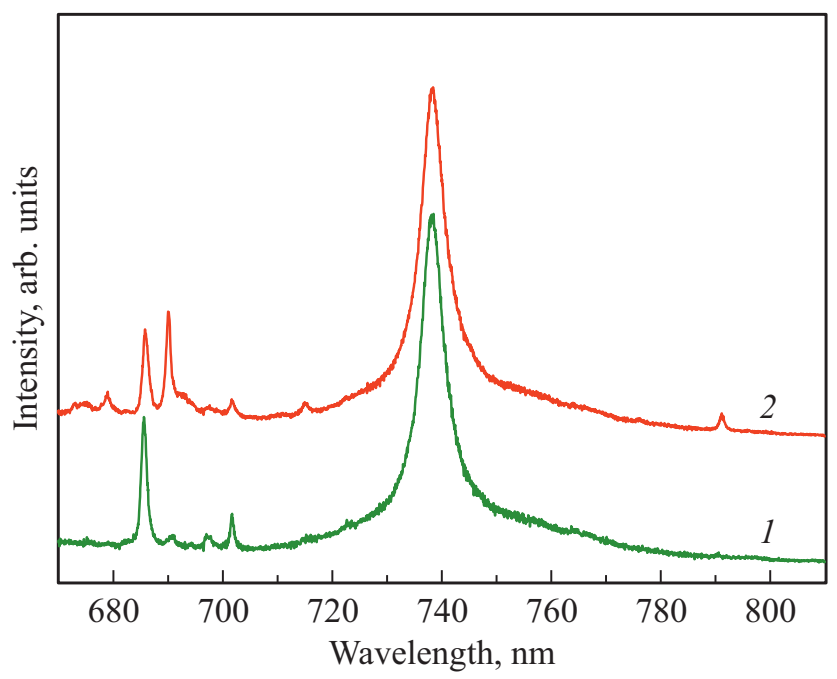

Рис. 2. Спектры ФЛ ансамбля наноалмазов, измеренные с использованием возбуждения $532 \mathrm{~nm}(1)$ и $633 \mathrm{~nm}$ (2). Спектры измерены при $T=300 \mathrm{~K}$ и нормированы на амплитуду линии центра окраски $\mathrm{SiV}^{-}$алмаза $(738.1 \mathrm{~nm})$. Плотность мощности возбуждающего излучения $5 \cdot 10^{3} \mathrm{~W} / \mathrm{cm}^{2}$.

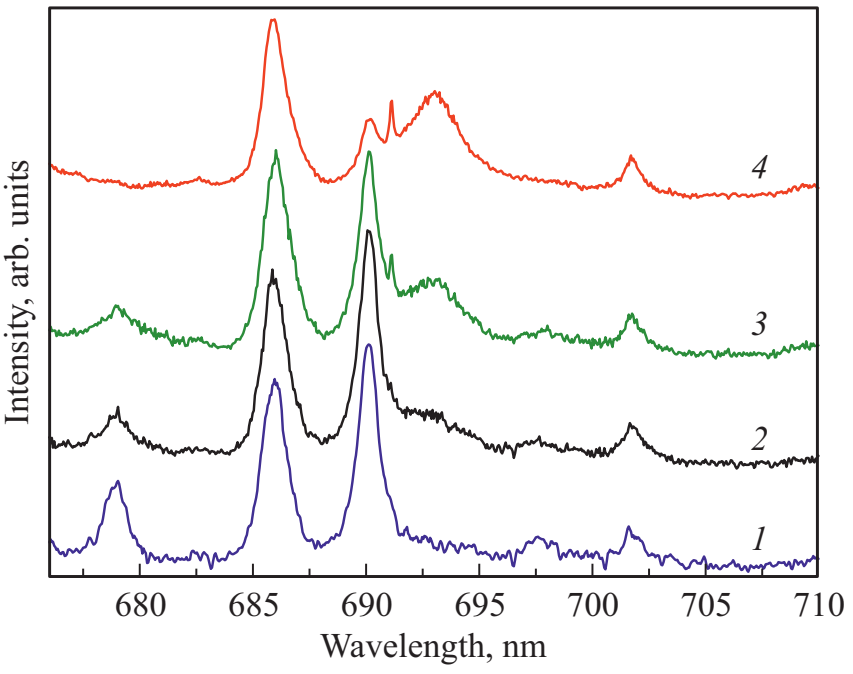

Рис. 3. Спектры ФЛ ансамбля наноалмазов, измеренные с использованием возбуждения $633 \mathrm{~nm}$ при плотности мощности излучения $5 \cdot 10^{2} \mathrm{~W} / \mathrm{cm}^{2}(1), 5 \cdot 10^{3} \mathrm{~W} / \mathrm{cm}^{2}$ (2), $5 \cdot 10^{4} \mathrm{~W} / \mathrm{cm}^{2}(3), 1.2 \cdot 10^{5} \mathrm{~W} / \mathrm{cm}^{2}(4)$. Спектры измерены при $T=300 \mathrm{~K}$ и нормированы на амплитуду линии на длине волны $685.8 \mathrm{~nm}$

мазов излучением лазера. Поэтому, чтобы избежать изменений в спектре ФЛ вызванных нагревом, значение максимальной плотности мощности возбуждения в эксперименте не превышало $1.2 \cdot 10^{5} \mathrm{~W} / \mathrm{cm}^{2}$. С увеличением плотности мощности уменьшается отношение интенсивности линии $690.4 \mathrm{~nm}$ к интенсивности линии $685.8 \mathrm{~nm}$, возгорается линия $693.1 \mathrm{~nm}$ (ее интенсивность при плотности мощности $1.2 \cdot 10^{5} \mathrm{~W} / \mathrm{cm}^{2}$ превосходит интенсивность линии $690.4 \mathrm{~nm}$ ), затухает линия $678.9 \mathrm{~nm}$. Соотношение интенсивностей линий 685.8 и $701.8 \mathrm{~nm}$ практически не меняется. При плотностях мощности $5 \cdot 10^{4} \mathrm{~W} / \mathrm{cm}^{2}$ и $1.2 \cdot 10^{5} \mathrm{~W} / \mathrm{cm}^{2}$ в спектрах регистрируется узкая линия КРС алмаза на длине волны $691.1 \mathrm{~nm}\left(1332 \mathrm{~cm}^{-1}\right)$.

На рис. 4 приведены спектры ФЛ до и после облучения с использованием возбуждения 532 и $633 \mathrm{~nm} \mathrm{c}$ плотностью мощности $1.2 \cdot 10^{5} \mathrm{~W} / \mathrm{cm}^{2}$ в течение $2 \mathrm{~min}$. Спектры нормированы на амплитуду линии $685.8 \mathrm{~nm}$. При использовании возбуждения $532 \mathrm{~nm}$ после лазерного облучения изменилось соотношение интенсивностей линий 685.8 и $690.4 \mathrm{~nm}$, а линия $685.8 \mathrm{~nm}$ сдвинулась в длинноволновую область на $0.3 \mathrm{~nm}$. При возбуждении с использованием $633 \mathrm{~nm}$, после лазерного облучения сильно увеличилась относительная интенсивность линии $678.9 \mathrm{~nm}$ и незначительно уменьшилась интенсивность линии $690.4 \mathrm{~nm}$. Линия $701.8 \mathrm{~nm}$ исчезла после облучения на длине волны $633 \mathrm{~nm}$ и практически не изменила интенсивность при облучении на длине волны $532 \mathrm{~nm}$.

Из анализа экспериментальных данных следует, что появление узких линий в спектре ФЛ и соотношение их интенсивностей зависит от длины волны возбуждающего излучения. С увеличением плотности мощности 

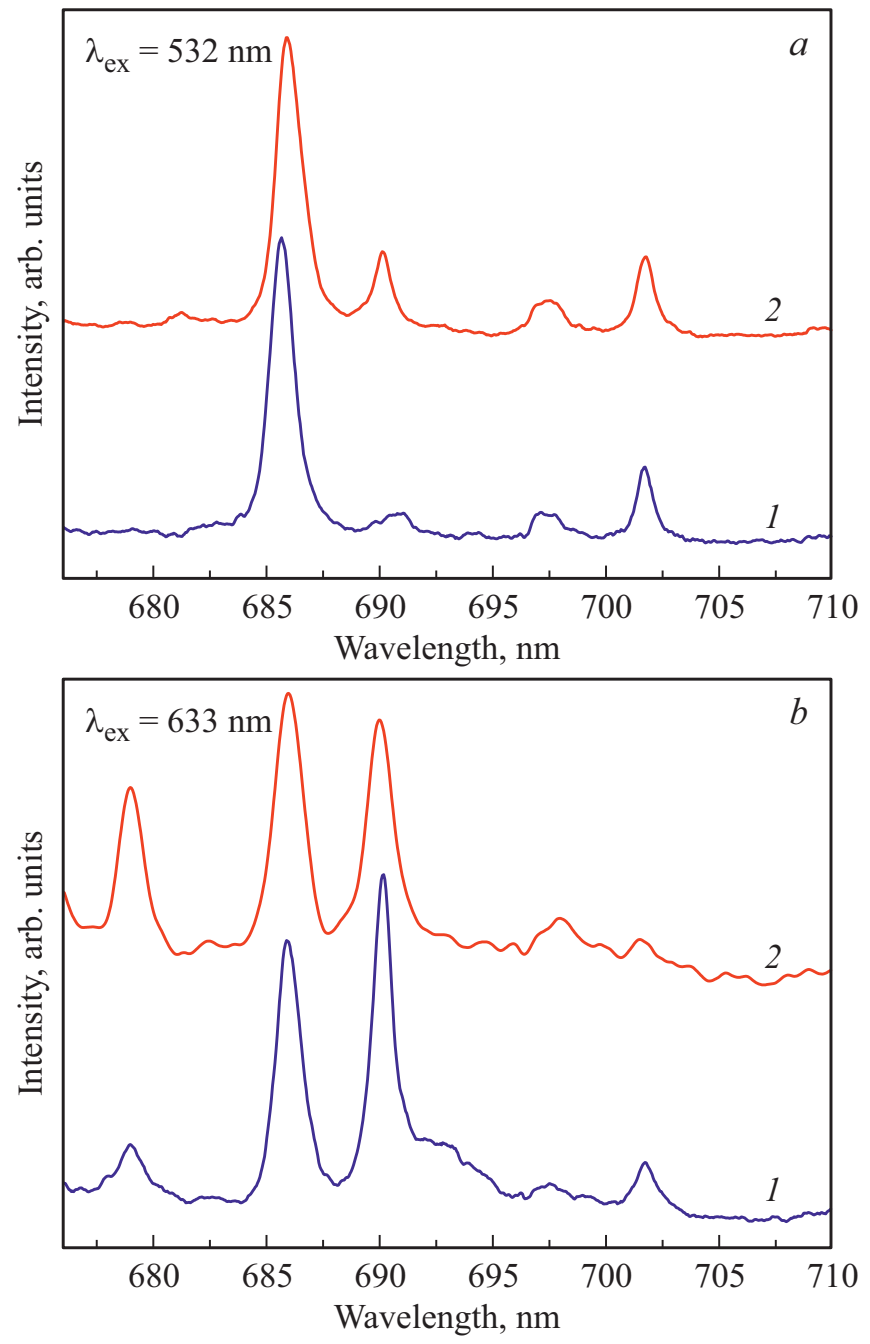

Pис. 4. Спектры ФЛ ансамбля наноалмазов, измеренные при плотности мощности возбуждающего излучения $5 \cdot 10^{2} \mathrm{~W} / \mathrm{cm}^{2}$ до (1) и после (2) облучения при использовании возбуждения $532 \mathrm{~nm}(a)$ и $633 \mathrm{~nm}(b)$. Плотность мощности и длительность облучения $1.2 \cdot 10^{5} \mathrm{~W} / \mathrm{cm}^{2}$ и $2 \mathrm{~min}$, соответственно. Спектры измерены при $T=300 \mathrm{~K}$ и нормированы на амплитуду линии $685.8 \mathrm{~nm}$.

возбуждающего излучения изменяются относительные интенсивности линий ФЛ, при этом происходит как возгорание, так и полное гашение линий ФЛ.

Оптически активные центры, ответственные за наблюдаемые узкие линии ФЛ, вероятно, образуют локализованные состояния в запрещенной зоне алмаза. Зарядовое состояние центра определяется главным образом близостью к нему донорного или акцепторного дефекта, а не положением уровня Ферми [21]. Поэтому, одновременно могут существовать дефекты с различными зарядовыми состояниями. Наблюдаемые в работе изменения спектральных характеристик линий ФЛ при варьировании параметров возбуждающего излучения могут быть следствием процессов фотоионизации, при которых под воздействием излучения происходит изменение зарядового состояния центров, ответственных за эти линии ФЛ. При изменении зарядового состояния под действием возбуждающего излучения изменяется энергия излучательного перехода центра, или он становится оптически неактивным.

Для центров в алмазе с известной электронной структурой [22-26] могут реализовываться прямой и непрямой механизмы фотоионизациии. Прямые фотоиндуцированные изменения центров зависят от длины волны возбуждающего излучения. Если энергия возбуждения меньше энергии фотоионизации, то происходит двух фотонная ионизация. При поглощении первого фотона центр переходит в возбужденное состояние, затем при поглощении второго фотона происходит заброс электрона из возбужденного состояния в зону проводимости, и центр изменяет заряд. При энергии фотона больше энергии фотоионизации центра происходит однофотонный процесс фотоионизации за счет заброса электрона в зону проводимости. В случае реализации непрямого механизма фотоионизации оптические центры могут менять зарядовое состояние за счет захвата электронов и дырок, образующихся в зоне проводимости и валентной зоне из-за фотоионизации других дефектных центров. Поскольку, положения энергетических уровней центров, ответственных за наблюдаемые узкие линии ФЛ, в запрещенной зоне алмаза не известны, особенности механизма их фотоионизации требует дальнейших исследований.

Причиной зависимости относительной интенсивности линий ФЛ от длины волны возбуждения может также быть зависимость сечения поглощения оптическим центром от длины волны возбуждения [22].

Сдвиг спектральных положений линий ФЛ (рис. 4) после облучения с плотностью мощности $1.2 \cdot 10^{5} \mathrm{~W} / \mathrm{cm}^{2}$ может быть вызван изменениями электрического или деформационного полей в месте расположения оптически активного центра, отвечающего за данную линию. Такие изменения могут быть связаны с флуктуацией электронных состояний дефектов в окрестности оптически активных центров при поглощении дефектами возбуждающего излучения.

Проведенный анализ температурных зависимостей спектров ФЛ различных ансамблей наноалмазов показал, что в спектрах регистрируются линии, которые условно можно отнести к трем типам: a) присутствующие во всем исследованном температурном диапазоне $T=79-300 \mathrm{~K}$; б) линии, наблюдаемые от $79 \mathrm{~K}$ и температуры ниже $300 \mathrm{~K}$; в) линии, зарегистрированные только в определенном диапазоне температур выше 79 K и ниже $300 \mathrm{~K}$. В качестве примера на рис. 5 приведены спектры ФЛ ансамбля наноалмазов в диапазоне температур 79-300 K, содержащие все три перечисленных типа линий. Спектры нормированы на амплитуду линии КРС алмаза $572.5 \mathrm{~nm}$. Во всем температурном диапазоне наблюдается линия, которая изменяет спектральное положение максимума и ширину с $685.1(0.2) \mathrm{nm}$ при $T=79 \mathrm{~K}$ до $685.8(0.96) \mathrm{nm}$ при 


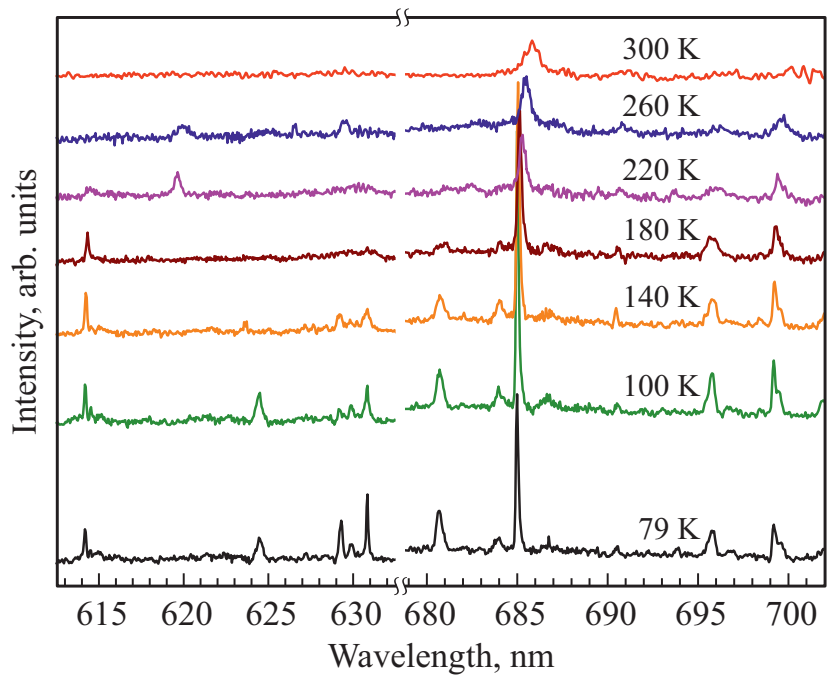

Рис. 5. Спектры ФЛ ансамбля наноалмазов, измеренные в диапазоне температур $T=79-300 \mathrm{~K}$ с использованием возбуждения $532 \mathrm{~nm}$. Спектры нормированы на амплитуду линии КРС алмаза $572.5 \mathrm{~nm}$.

$T=300 \mathrm{~K}$. В диапазоне температур, начиная с $T=79 \mathrm{~K}$ и до температур ниже $T=300 \mathrm{~K}$, наблюдаются линии $614.2,624.5,680.6$ и $695.8 \mathrm{~nm}$, три близко расположенные линии $629.3,629.9$ и $630.8 \mathrm{~nm}$, слабая линия $683.9 \mathrm{~nm}$, две близко расположенные линии 699.2 и $699.6 \mathrm{~nm}$. Спектральное положение линий указано при $T=79 \mathrm{~K}$.

Линия $614.2(0.16) \mathrm{nm}$ сдвигается и уширяется до $614.3(0.22) \mathrm{nm}$ при $T=180 \mathrm{~K}$, при этом ее интенсивность практически не изменяется. Выше $T=220 \mathrm{~K}$ эта линия в спектрах ФЛ не наблюдается. Линия $624.5 \mathrm{~nm}$ не наблюдается уже при температуре $T>100 \mathrm{~K}$. Три близко расположенные линии 629.3, 629.9 и $630.8 \mathrm{~nm}$ не наблюдаются при $T=180 \mathrm{~K}$. Линия $680.6(0.16) \mathrm{nm}$ сдвигается и уширяется до $680.7(0.22) \mathrm{nm}$ при $T=140 \mathrm{~K}$. Выше $T=220 \mathrm{~K}$ эта линия в спектрах не наблюдается. Линия 695.8 (0.5) nm также испытывает длинноволновый сдвиг и уширение до 695.9 (0.7) nm при увеличении температуры до $T=220 \mathrm{~K}$ и не наблюдается выше $T=260 \mathrm{~K}$. Две близко расположенные линии 699.2 и $699.6 \mathrm{~nm}$ с увеличением температуры становятся практически неразличимы и при $T=260 \mathrm{~K}$ образуют общий контур с максимумом на длине волны $699.7 \mathrm{~nm}$. При $T=220 \mathrm{~K}$ обнаружено возгорание узкой линии $619.6 \mathrm{~nm}$ и наблюдается ее сдвиг до $619.9 \mathrm{~nm}$ при $T=260 \mathrm{~K}$. При $T=300 \mathrm{~K}$ эта линия не регистрируется.

Наблюдаемое с ростом температуры уменьшение амплитуды узких линий ФЛ и их полное гашение может быть связано с температурной активацией безызлучательных каналов рекомбинации [27]. Из анализа температурных зависимостей интенсивности линий ФЛ, можно сделать вывод, что центры ответственные за эти линии, обладают различными по величине энергиями активации безызлучательных переходов. Чем выше энергия активации безызлучательных переходов, тем при более высоких температурах возможно регистрировать линии ФЛ.

Обнаруженное возгорание узкой линии ФЛ на длине волны $619.6 \mathrm{~nm}$ при $T=220 \mathrm{~K}$ может быть приписано термически активируемой ионизации, при которой происходит изменение зарядового состояния центра, и в результате, он становится оптически активным.

Как и для хорошо известных центров окраски азот-вакансия и кремний-вакансия $[28,29]$ сдвиг положения максимума узких линий ФЛ в длинноволновую область спектра с увеличением температуры, по-видимому, является следствием совокупного вклада температурного расширения кристаллической решетки и электрон-фононного взаимодействия. За регистрируемое в спектрах однородное уширение линий ФЛ с ростом температуры ответственно квадратичное электронфононное взаимодействие [30].

\section{4. Заключение}

В работе исследованы зависимости спектральных характеристик узких линий ФЛ в наноалмазах от параметров возбуждающего излучения и температуры. Наноалмазы получены путем реактивного ионного травления в кислородной плазме алмазных частиц, синтезированных методом MWCVD на кремниевой подложке. Соотношение интенсивностей узких линий в спектрах ФЛ наноалмазов зависит длины волны возбуждающего излучения. Показано, что с увеличением плотности мощности возбуждающего излучения изменяются относительные интенсивности линий. Обнаружены линии, которые с увеличением плотности мощности возбуждения сдвигаются в длинноволновую область и уширяются. Выявленные зависимости спектральных характеристик линий от параметров возбуждающего излучения, по-видимому, обусловлены процессами фотоионизации. Под воздействием возбуждающего излучения происходит изменение зарядового состояния центров, ответственных за наблюдаемые линии ФЛ, что и приводит к наблюдаемому возгоранию или гашению сигнала люминесценции.

Показано, что в спектрах ФЛ наноалмазов имеются линии, которые условно можно отнести к трем типам: a) присутствующие во всем температурном диапазоне $T=79-300 \mathrm{~K}$, б) линии, наблюдаемые только при температурах ниже $T=300 \mathrm{~K}$, в) линии, зарегистрированные только в определенном диапазоне температур выше $79 \mathrm{~K}$ и ниже $300 \mathrm{~K}$. С ростом температуры в диапазоне 79-300 K происходит сдвиг линий ФЛ в длинноволновую область и увеличение их ширины.

\section{Финансирование работы}

Работа выполнена с использованием средств госбюджета по теме госзадания 0040-2019-0012. 


\section{Конфликт интересов}

Авторы заявляют, что у них нет конфликта интересов.

\section{Список литературы}

[1] C. Bradac, W. Gao, J. Forneris, M. Trusheim, I. Aharonovich. Nature Commun. 10, 5625 (2019).

[2] I. Aharonovich, E. Neu. Adv. Opt. Mater. 2, 10, 911 (2014).

[3] Z. Ju, J. Lin, S. Shen, B. Wu, E. Wu. Adv. Phys. X 6, 1, 1858721 (2021).

[4] I. Aharonovich, S. Castelletto, D.A. Simpson, C.H. Su, A.D. Greentree, S. Prawer. Rep. Prog. Phys. 74, 076501 (2011).

[5] O.A. Shenderova, A.I. Shames, N.A. Nunn, M.D. Torelli, I. Vlasov, A. Zaitsev. J. Vac. Sci. Technol. B 37, 030802 (2019).

[6] M. Radulaski, J.L. Zhang, Y.-K. Tzeng, K.G. Lagoudakis, H. Ishiwata, C. Dory, K.A. Fischer, Y.A. Kelaita, S. Sun, P.C. Maurer, K. Alassaad, G. Ferro, Z.-X. Shen, N.A. Melosh, S. Chu, J. Vuckovic. Laser Photon. Rev. 13, 8, 1800316 (2019).

[7] M.H. Alkahtani, F. Alghannam, L. Jiang, A. Almethen, A.A. Rampersaud, R. Brick, C.L. Gomes, M.O. Scully, P.R. Hemmer. Nanophotonics 7, 8, 1423 (2018).

[8] T. Müller, I. Aharonovich, L. Lombez, Y. Alaverdyan, A.N. Vamivakas, S. Castelletto, F. Jelezko, J. Wrachtrup, S. Prawer, M. Atatüre. New J. Phys. 13, 075001 (2011).

[9] D. Steinmetz, E. Neu, J. Meijer, W. Bolse, C. Becher. Appl. Phys. B 102, 3, 451 (2011).

[10] R.G. Sandstrom, O. Shimoni, A.A. Martin, I. Aharonovich. Appl. Phys. Lett. 105, 181104 (2014).

[11] K. Ganesan, P.K. Ajikumar, S. Ilango, G. Mangamma, S. Dhara. Diam. Rel. Mater. 92, 150 (2019).

[12] D.W.M. Lau, T.J. Karle, B.C. Johnson, B.C. Gibson, S. Tomljenovic-Hanic, A.D. Greentree, S. Prawer. APL Mater. 1, 032120 (2013).

[13] D.G. Monticone, P. Traina, E. Moreva, J. Forneris, P. Olivero, I. Degiovanni, F. Taccetti, L. Giuntini, G. Brida, G. Amato, M. Genovese. New J. Phys. 16, 053005 (2014).

[14] K. Bray, R. Sandstrom, C. Elbadawi, M. Fischer, M. Schreck, O. Shimoni, C. Lobo, M. Toth, I. Aharonovich. ACS Appl. Mater. Interfaces. 8, 7590 (2016).

[15] T.T. Tran, M. Kianinia, K. Bray, S. Kim, Z.-Q. Xu, A. Gentle, B. Sontheimer, C. Bradac, I. Aharonovich. APL Photonics 2, 116103 (2017).

[16] В.Г. Голубев, С.А. Грудинкин, В.Ю. Давыдов, А.Н. Смирнов, Н.А. Феоктистов. ФТТ 59, 12, 2382 (2017).

[17] Н.А. Феоктистов, В.И. Сахаров, И.Т. Серенков, В.А. Толмачев, И.В. Коркин, А.Е. Алексенский, А.Я. Вуль, В.Г. Голубев. ЖТФ 81, 5, 132 (2011).

[18] S.A. Grudinkin, N.A. Feoktistov, M.A. Baranov, A.N. Smirnov, V.Y. Davydov, V.G. Golubev. Nanotechnol. 27, 395606 (2016).

[19] S.A. Grudinkin, N.A. Feoktistov, V.G. Golubev. J. Phys.: Conf. Ser. 1400, 066011 (2019).

[20] S. Prawer, R.J. Nemanich. Phil. Trans. R. Soc. A 362, 1824, 2537 (2004).

[21] A.T. Collins. J. Phys. Condens. Matter 14, 14, 3743 (2002).

[22] N. Aslam, G. Waldherr, P. Neumann, F. Jelezko, J. Wrachtrup. New J. Phys. 15, 013064 (2013).
[23] N. Manson, J. Harrison. Diam. Relat. Mater. 14, 10, 1705 (2005).

[24] J. Görlitz, D. Herrmann, G. Thiering, P. Fuchs, M. Gandil, T. Iwasaki, T. Taniguchi, M. Kieschnick, J. Meijer, M. Hatano, A. Gali, C. Becher. New J. Phys. 22, 013048 (2020).

[25] U.F.S. D'Haenens-Johansson, A.M. Edmonds, B.L. Green, M.E. Newton, G. Davies, P.M. Martineau, R.U.A. Khan, D.J. Twitchen. Phys. Rev. B 84, 245208 (2011).

[26] K. Iakoubovskii, G.J. Adriaenssens, M. Nesladek. J. Phys.: Condens. Matter 12, 2, 189 (2000).

[27] T. Feng, B.D. Schwartz. J. Appl. Phys. 73, 3, 1415 (1993).

[28] M.W. Doherty, V.M. Acosta, A. Jarmola, M.S.J. Barson, N.B. Manson, D. Budker, L.C.L. Hollenberg. Phys. Rev. B 90, 041201 (2014).

[29] M. Zaghrioui, V.N. Agafonov, V.A. Davydov. Mater. Res. Express 7, 15043 (2020).

[30] G. Davies. Reports Prog. Phys. 44, 7, 787 (1981).

Редактор Т.Н. Василевская 